\title{
Phylogenetic analysis of two new complete genomes of the hepatitis $E$ virus (HEV) genotype 3 from Thailand
}

\author{
Tipsuda Chanmanee ${ }^{1}$. Pravech Ajawatanawong ${ }^{2} \cdot$ Suda Louisirirotchanakul $^{1} \cdot$ Watcharasak Chotiyaputta $^{3}$. \\ Siwaporn Chainuvati ${ }^{3} \cdot$ Patimaporn Wongprompitak ${ }^{4}$ (1)
}

Received: 11 November 2019 / Accepted: 8 October 2020 / Published online: 14 October 2020

(c) The Author(s) 2020

\begin{abstract}
Hepatitis E virus (HEV) is a causative agent of acute viral hepatitis globally. Evolutionary phylogeny classifies the HEV into eight genotypes that correlate with the viral transmission. Only four genotypes have been proven to be responsible for transmission in humans. However, there has been no report on the genomics and genotyping of HEV in Thailand during the past ten years. Here, we identified the genotype distributions of the Thai isolates of HEV and we sequenced two HEV genomes. We screened for 18 Thai isolates of HEV from Siriraj Hospital in Bangkok, from 2014-2016. The HEV genomes were sequenced from the serum and feces of a patient. The results showed that all Thai isolates of HEV were identified as genotype 3 (HEV-3). The ORF2 and genome phylogenies suggested two subgenotypes, called 3.1 and 3.2. The Thai isolates of HEV were frequently found in the subgenotype 3.1. The genome sequences of the two Thai isolates of HEV from the serum and fecal samples of the same patient showed $91 \%$ nucleotide similarity with the HEV genotype 3. Comparisons between the HEV genome and the ORF2 phylogenies illustrated that the ORF2 tree can be used to identify HEV genotypes, but it has less phylogenetic power for the HEV evolution. The two new genome sequences of HEV-3 from Thailand could contribute valuable information to the HEV genome study. (226 words)
\end{abstract}

Keywords Hepatitis E virus $\cdot$ HEV genotype $\cdot$ HEV genotype $3 \cdot$ Complete genome sequence $\cdot$ Phylogeny

\section{Introduction}

Hepatitis E virus (HEV) or Orthohepevirus A is an emerging viral infection that causes acute hepatitis, which is considered as leading to a low rate of mortality and not developing into chronic hepatitis [1]. However, the incidence of chronic

Tipsuda Chanmanee and Pravech Ajawatanawong are co-first author and also contributed equally to this work.

Patimaporn Wongprompitak

patimaporn.won@mahidol.ac.th

1 Department of Microbiology, Faculty of Medicine Siriraj Hospital, Mahidol University, Bangkok, Thailand

2 Division of Bioinformatics and Data Management for Research, Faculty of Medicine Siriraj Hospital, Mahidol University, Bangkok, Thailand

3 Division of Gastroenterology, Department of Medicine, Faculty of Medicine Siriraj Hospital, Mahidol University, Bangkok, Thailand

4 Department of Immunology, Faculty of Medicine Siriraj Hospital, Mahidol University, Bangkok, Thailand hepatitis appears to be increasing among immunocompromised patients who have had an organ transplant, in developing countries, particularly industrial countries [2,3]. The virus transmits when people consume contaminated food or water [1]. There are two main laboratory-detection methods for HEV. One is the molecular-based method using reverse transcription-PCR, which is generally targeted at the viral capsid protein. Another is the immunological-based method for the detection of IgM and IgG against HEV antigens [4].

HEV is classified as a member in the genus Orthohepevirus of the family Hepeviridae. The structure of HEV particle is comprised of a positive, single-stranded RNA genome packed inside the icosahedral capsid proteins [5]. Genome of the virus has $\sim 7.2$ bases in length, including a 5'-untranslated region ( $5^{\prime}$-UTR), three open reading frames (ORFs), and a 3 '-untranslated region (3'-UTR). The ORF1 contains at least four nonstructural proteins, including a methyltransferase, a cysteine protease, a helicase, and an RNA-dependent RNA polymerase [6]. ORF2 is laid behind the ORF1 and encodes a capsid antigen protein. The ORF3, the smallest 
ORF, which is overlapped with the ORF2, encoded a protein with an unknown function [6].

Phylogenetic analysis of the HEV genomic sequences illustrated the virus are highly diverged into eight genotypes. The HEV genotype 1 and 2 are closely related genotypes [7, 8]. The genotype 1 can be found in Asia, Africa, and South America, whereas the genotype 2 are found in Mexico, Nigeria, and Chad [9]. The viruses in both genotypes mainly infected humans, so-called "anthropotropic genotypes", and transmitted by contamination in supply water [8]. The HEV genotype 3 are spread globally. The HEV genotype 4 is found to be limited in East Asia, including Japan, China, and South Korea [10, 11]. The HEV in both genotype 3 and 4 are found as sporadic infection in human, pigs, and other animals $[6,10]$. Chronic hepatitis may develop in immunosuppressed patients infected with HEV genotypes 3 or 4 [6]. The viral transmission occurs by ingestion of raw or undercooked meat from infected animals, so-called "enzootic genotypes". Unlike the major genotypes, the HEV genotype 5-8 are small groups and found in animals. HEV genotypes 5 and 6 are the isolates from wild boars in Japan; HEV genotype 7 was identified from dromedary camels in the United Arab Emirates and other countries in the Middle East; HEV genotype 8 comes from camels and circulates in many regions in China [6, 10-13].

For this study, we observed HEV RNA among 18 acute HEV patients in Thailand from 2014 to 2016. In fact, there are few studies of HEV phylogenies in Thailand particularly in a comparison between ORF2 and genome phylogenetic trees. This observation was done in Thailand after the last survey, which was done about a decade ago [14, 15]. The partial ORF2 were sequenced and we performed phylogenetic reconstruction for HEV genotype identification. Of those 18 patients, only one had adequate serum and fecal specimens for whole-genome sequencing. The complete HEV genome sequences were subjected to phylogenetic reconstruction to determine of the HEV genome evolution, as well.

\section{Materials and methods}

\section{Subjects and samples}

Hepatitis patients who admitted to the hospital at the Faculty of Medicine Siriraj Hospital, Mahidol University in Bangkok from 2014 to 2016, were investigated for HEV. All patients tested positive for hepatitis, specifically due to their elevation of two liver enzymes, aspartate aminotransferase (AST) and alanine transaminase (ALT). The serum and feces were collected from all 33 hepatitis patients to investigate the antibodies against HEV and viral HEV RNA. The serological markers with anti-HEV IgM and IgG were detected by indirect ELISA (DIA.PRO, Milan, Italy) based on the HEV-specific antigens of four HEV genotypes. Sera and fecal specimens were used to detect HEV RNA by PCR of a 0.9-kb-region in the ORF2. However, the serum and fecal samples from all these patients were taken on the same day.

Only one sample (from patient number TH-hu-45) had enough RNA for a genome sequencing. This person was 68 years old, and had developed an abnormal liver function, with an increase in three liver markers, including alanine transaminase (ALT) at the level of $640 \mathrm{U} / \mathrm{L}$; aspartate transaminase (AST) at the level of $165 \mathrm{U} / \mathrm{L}$; and alkaline phosphatase (ALP) at the level of $310 \mathrm{U} / \mathrm{L}$. The Ethics Committee approved the protocol used in this study for Research in Humans of the Faculty of Medicine Siriraj Hospital, Mahidol University (IRB no. Si 699/2014). Written informed consent was obtained from all the participating patients.

\section{Amplification of HEV RNA for detection and nucleotide sequencing}

The HEV RNA was extracted from $140 \mu \mathrm{l}$ of the specimen using a QIAmp Viral RNA Mini Kit (QIAGEN, Hilden, Germany). The complementary DNA (cDNA) was synthesized from HEV RNA by reverse transcription with a Superscript III First-Strand Synthesis System (Invitrogen, Carlsbad, CA, USA) using a random hexamer. The cDNA was used for the determination and sequencing of HEV ORF2. For HEV determination, the first round nested PCR of the ORF2 fragment was amplified by HE361 (5'-GCRGTGGTT TCTGGGGTGAC-3') and HE364 (5'-CTGGGMYTGGTC DCGCCAAG- $3^{\prime}$ ) primers. The second-round PCR then followed the PCR amplicons with HE366 (5'-GYTGATTCT CAGCCCTTCGC-3') and HE363 (5'-GMYTGGTCDCGC CAAGHGGA-3') primers $[15,16]$. The PCR contained $5 \mu \mathrm{L}$ of DNA template, $5 \mu \mathrm{L}$ of 10xPCR buffer, $4 \mu \mathrm{L}$ of $25 \mathrm{mM}$ dNTP, $0.5 \mu \mathrm{L}$ of $5 \mathrm{U} / \mu \mathrm{L}$ EX TaKaRa Taq (TaKaRa Bio, Inc., Shiga, Japan), $20 \mathrm{pmol}$ of forward and reverse primers, and was adjusted a final volume of $50 \mu \mathrm{L}$ by DNase-RNase-free distilled water. PCR was performed for 35 cycles of $94{ }^{\circ} \mathrm{C}$ for 30 seconds; $55^{\circ} \mathrm{C}$ for 30 seconds; and $72{ }^{\circ} \mathrm{C}$ for one minute. The second round was amplified for 25 cycles under the same amplification conditions. The expected size of the final PCR amplicon was 137 base pairs (bp) in length.

In case of nucleotide sequencing of HEV ORF2, we needed a longer PCR amplicon (919 bp), which contained enough phylogenetic signals in the sequences. The entire cDNA samples were performed semi-nested PCR using HE6209F (5'-CAGCCACACGTTTYATGAAGGA-3') and HE3' (5'-TTTTTTTTCCAGGGAGCG-3') as the outer primers. The inner primers were HE6326F (5'-CGACAGAAT TGATTTCGTCGGC- $3^{\prime}$ ) and HE3' primers. The PCR products of the first and second round had a size of $1036 \mathrm{bp}$ and 
919 bp, respectively. The PCR amplicons were purified by QIAquick Gel Extraction Kit (QIAGEN).

\section{HEV genome sequencing and assembly}

To sequence the HEV genome, 12 sets of oligonucleotide primers (Table 1) were designed overlappingly along the genome as the genome sequencing strategy. After we determine the concentration of HEV cDNA left-over from RNA determination, one left over cDNA from a patient, TH-hu45 , had enough concentration for genome sequencing. The cDNA from this fecal sample was coded as TH-hu-F45-1. Fortunately, we also had cDNA from the serum sample (THhu-S45-1) of the same patient. The fecal and serum samples were taken from the subject on the same day.

The PCR amplification conditions were varied by the melting temperature of each pair of primers. The PCR amplicons for each pair of primers were purified using the QIAquick Gel Extraction Kit (QIAGEN). The purified PCR amplicons were cloned into the pCRTM2.1-TOPO vector (Invitrogen). The nucleotide sequencing was performed using Sanger's sequencing by M13 forward and reverse primers (Macrogen, Seoul, South Korea). All PCR amplicons were sequenced in both strands to prevent sequencing errors. All sequence electropherograms were read and edited manually. The edited sequences from both strands were confirmed by BLASTN and consensus sequences by the SeaView program version 5.0.4 [17]. The $12 \mathrm{HEV} \mathrm{frag-}$ ments were assembled manually.

\section{Phylogenetic analyses}

The 19 sequences of the HEV partial ORF2 sequences (accession number: MH427090-MH427106, KY232312, KY232313) and 43 sequences (accession number: AB369687, EU723513, EU360977, KJ873911, AB290313, AB248521, AF455784, FJ705359, FJ998008, AB290312, JQ953664, JQ013794, AF082843, AP003430, AY115488, AB369689, AB220974, GU119961, AB108537, AB369688, AB074915, DQ450072, AB197673, AJ272108, AY723745, DQ279091, AB602441, AB856243, AB573435, M73218, JF443721, X98292, AY230202, AY204877, D11092, M74506, KJ496143, KJ496144, JQ013791, FJ906895, KJ013415, LC177788, and NC038504) of HEV ORF2 in the other study [18] were used as the dataset for a phylogenetic analysis of the partial ORF2 sequences. All sequences were aligned by the MUSCLE program $[19,20]$ via the SeaView program [17]. The multiple sequence alignment (MSA) was trimmed only at $5^{\prime}$ - and 3 '-terminals. The size of the final matrix was 568 characters $\times 62$ taxa. The phylogenetic analyses were performed by the maximum likelihood (ML) method using the PhyML program [21] via the SeaView program [17], and Bayesian Inference (BI) method using
MrBayes version 3.2.7 [22]. The ML tree was run with the GTR + I + G model. The bootstrap values were calculated from 1000 replications of pseudodata. The BI tree was run with 1,000,000 generations or until the average standard deviation of the split frequencies fell below 0.01 . The trees were sampled with every 100 generations, and a total of 20,000 trees were generated with the initial sample. The trees were edited with FigTree version 1.4.4 [23].

The dataset of the HEV genome sequences for phylogenetic reconstruction contains two complete sequences from our study (accession number: KY232312 and KY232313) and another 95 genome sequences from the other studies (accession numbers: AB074918, AB074920, AB089824, AF082843, AY115488, AP003430, AB189070, AB091394, AB073912, AB369689, AB740232, KC618403, KC618402, FJ705359, KJ701409, FJ998008, JQ013794, AB290312, JQ953664, AB369687, FJ653660, AB291961, EU375463, FJ956757, KC166971, EU723513, EU360977, AB290313, AB248521, KJ013415, AB248522, HM055578, FJ998015, KF922359, JQ013795, AF455781, FJ906895, JQ013791, KJ496143, KJ496144, AF076239, AF459438, X99441, AF051830, M73218, D10330, AF185822, JF443721, L08816, M94177, L25595, AF444003, D11092, D11093, X98292, AY230202, AY204877, M74506, AB161791, AB220972, AB220973, AB220975, AB074917, AB161717, AB220977, AB220979, AB220976, AB099347, AB193176, AB193178, AB193177, AB200239, AB220971, AB097811, AB080575, AB074915, GU119961, AB220974, AB108537, AB369688, DQ279091, EU676172, AB253420, AJ272180, AY594199, AB197674, EF077630, AB197673, AY723745, DQ450072, AB602441, AB856243, AB573435, LC177788, NC038504) [15, 24-73]. The dataset was aligned with the same method for analysis of the ORF2 region. Phylogenetic analysis was done with both ML and BI, using the same setting parameters as the ORF2 phylogeny.

\section{Results}

\section{Serological and molecular detection of HEV in Thai patients}

The 33 serum samples were collected from 33 patients with hepatitis, who showed an abnormal liver function, based on the enzymes, aspartate aminotransferase (AST) and alanine transaminase (ALT). All serum samples were screened for $\operatorname{IgM}$ and $\operatorname{IgG}$ by the ELISA method. Of the 33 patients, only 20 samples $(60.6 \%)$ were diagnosed as HEV infection (Table 2) by either positive for IgM or IgG, or positive for both. The sample TH-hu-FPP was negative for IgM but positive for IgG.

The 20 HEV patients were then tested for HEV RNA, using their serum and feces. Only 18 patients were positive 
Table 1 A list of the 12 oligonucleotide primer sets used for hepatitis E virus (HEV) whole-genome-sequence amplification

\begin{tabular}{|c|c|c|c|c|c|c|c|}
\hline Set & Outer/inner & Primer & Oligonucleotide primer sequence & Region & Position & Product size (bp) & $\mathrm{Ta}\left({ }^{\circ} \mathrm{C}\right)$ \\
\hline \multirow[t]{4}{*}{1} & \multirow[t]{2}{*}{ Outer } & HE5 & GTC GAT GCC ATG GAG GCC & \multirow[t]{4}{*}{ 5'UTR/ORF1 } & $1-18$ & \multirow[t]{2}{*}{543} & 54 \\
\hline & & HE52 & CCG AGG GCC AAA GGT CAT G & & $525-543$ & & 53 \\
\hline & \multirow[t]{2}{*}{ Inner } & HE5' & GTC GAT GCC ATG GAG GCC & & $1-18$ & \multirow[t]{2}{*}{473} & 54 \\
\hline & & HE452 & CCC ATC GAA GCA GTA TGT GCG & & $452-473$ & & 53 \\
\hline \multirow[t]{4}{*}{2} & \multirow[t]{2}{*}{ Outer } & HE01 & AAG GCT CCT GGC ATT ACT ACT & \multirow[t]{4}{*}{ ORF1 } & $48-70$ & \multirow[t]{2}{*}{955} & 53 \\
\hline & & HE02 & AAR AGC ATR AGC CGR TCT CA & & $984-1003$ & & 51 \\
\hline & \multirow[t]{2}{*}{ Inner } & HE01 & AAG GCT CCT GGC ATT ACT ACT & & $48-70$ & \multirow[t]{2}{*}{901} & 53 \\
\hline & & HE03 & GTA GAG CAR GCT GAK GGR AA & & $930-949$ & & 51 \\
\hline \multirow[t]{4}{*}{3} & \multirow[t]{2}{*}{ Outer } & HE741F & TGG ATC CGC ACC ACT AAA ATA & \multirow[t]{4}{*}{ ORF1 } & $741-761$ & \multirow[t]{2}{*}{1173} & 52 \\
\hline & & HE1895Rst & CGG TRC AAT CCA RGC CAT TA & & $1895-1914$ & & 52 \\
\hline & \multirow[t]{2}{*}{ Inner } & HE741F & TGG ATC CGC ACC ACT AAA ATA & & $741-761$ & \multirow[t]{2}{*}{1000} & 52 \\
\hline & & HE1722Rn & AAG RCC TTA TTC CCG AGC AC & & $1722-1741$ & & 56 \\
\hline \multirow[t]{4}{*}{4} & \multirow[t]{2}{*}{ Outer } & HE1498Fst & TGG TTG GTG ACT GTG GCC AT & \multirow[t]{4}{*}{ ORF1 } & $1498-1517$ & 877 & 55 \\
\hline & & HE2293Rst & TGG TGT RGG CGG CTT ACG G & & $2357-2375$ & & 56 \\
\hline & Inner & HE1560Fn & CCC GCC CAC CTT GAT GTT TC & & $1560-1579$ & 815 & 55 \\
\hline & & HE2293Rn & TGG TGT RGG CGG CTT ACG G & & $2357-2375$ & & 56 \\
\hline 5 & Outer & HE1990F & ACA ATA GGT TCA CCC AGC GCC & ORF1 & 1990-2010 & 1085 & 55 \\
\hline & & HE3054Rst & GTC GCC AAC TAT TGC GGA GCT C & & $3054-3075$ & & 55 \\
\hline & Inner & HE1990F & ACA ATA GGT TCA CCC AGC GCC & & 1990-2010 & 1016 & 55 \\
\hline & & HE2985Rn & TAG ACT TTC CGG AGC CGG GAA C & & $2985-3006$ & & 55 \\
\hline 6 & Outer & FfrR4st & GTC GAT GCC ATG GAG GCC & ORF1 & $2795-2815$ & 1007 & 54 \\
\hline & & FfrR4n' & CCG AGG GCC AAA GGT CAT G & & $3783-3802$ & & 55 \\
\hline & Inner & FfrR4st & GTC GAT GCC ATG GAG GCC & & $2795-2815$ & 944 & 54 \\
\hline & & RfrR4 & CCC ATC GAA GCA GTA TGT GCG & & $3783-3802$ & & 55 \\
\hline 7 & Outer & HE3560Fst & TGC GCA TGC TAT CGT TGC ACT & ORF1 & $3560-3580$ & 956 & 55 \\
\hline & & HE4497R & GGC ATG CCA CAY TCC TCC AT & & $4497-4516$ & & 55 \\
\hline & Inner & HE3664Fn & ACT TCT TCC TGG CTG GTG GTG A & & $3664-2685$ & 852 & 55 \\
\hline & & HE4497R & GGC ATG CCA CAY TCC TCC AT & & $4497-4516$ & & 55 \\
\hline 8 & Outer & HE4263Fst & GCA TAT CGG CTT GGA GTA AGA C & ORF1 & $4263-4285$ & 816 & 52 \\
\hline & & HE5058R & AGT GGG CCT TTC CAT CAG CAA T & & $5058-5079$ & & 55 \\
\hline & Inner & HE4332Fn & ATT CTA GCT TTG CTC CCG CCC & & $4332-4352$ & 747 & 55 \\
\hline & & HE5058R & AGT GGG CCT TTC CAT CAG CAA T & & $5058-5079$ & & 55 \\
\hline 9 & Outer & HE4974F & CGC AGG TTT GTG TTG ATG TTG T & ORF1/ORF2 & 4974-4996 & 677 & 54 \\
\hline & & HE5631Rst & GGG GCG GCA TAC AAG ACA AGA & & $5631-5651$ & & 55 \\
\hline & Inner & HE4974F & CGC AGG TTT GTG TTG ATG TTG T & & $4974-4996$ & 610 & 54 \\
\hline & & HE5563Rn & TAT ACT GGC GGC GCA AGA TAG C & & $5563-5584$ & & 55 \\
\hline 10 & Outer & HE5204F & TCT TCG TGC TTC TGC CTA TGC TG & ORF2 & $5204-5226$ & 972 & 55 \\
\hline & & HE6159Rst & CCA CGA CGC AAA CGG TGT & & $6159-6176$ & & 54 \\
\hline & Inner & HE5204F & TCT TCG TGC TTC TGC CTA TGC TG & & $5204-5226$ & 855 & 55 \\
\hline & & HE6040Rn & CCG GTA TAG GGC GTG TTG GT & & $6040-6059$ & & 55 \\
\hline 11 & Outer & ORF2F2 & CHA TYT CTA TYT CYT TYT GGC C & ORF2 & $5890-5912$ & 955 & 56 \\
\hline & & ORF2R2 & GTA GTC TGR TCA TAY TCA GCV GC & & $6703-6725$ & & 55 \\
\hline & Inner & ORF2F2 & CHA TYT CTA TYT CYT TYT GGC C & & $5890-5912$ & 901 & 56 \\
\hline & & Cona1M & TCT TGT TCR TGY TGG TTR TCR TAR TC & & $6524-6499$ & & 55 \\
\hline 12 & Outer & HE6209Fst & CAG CCA CAC GTT TYA TGA AGG A & ORF2/3'UTR & $6209-6230$ & 1036 & 56 \\
\hline & & HE3prime & TTT TTT TTT TTT TTT TTT TCC AGG GAG CG & & $7220-7245$ & & 55 \\
\hline & Inner & HE6326Fn & CGA CAG AAT TGA TTT CGT CGG C & & $6326-6347$ & 919 & 56 \\
\hline & & HE3prime & TTT TTT TTT TTT TTT TTT TCC AGG GAG CG & & $7220-7245$ & & 55 \\
\hline
\end{tabular}


Table 2 Samples and sequences used in this study: each sample ID referrs to individual hepatitis patients

\begin{tabular}{llllllll}
\hline Sample ID & \multicolumn{3}{l}{ Anti-HEV } & \multicolumn{3}{l}{ HEV RNA } & Accession number \\
\cline { 2 - 4 } \cline { 5 - 6 } & IgM & IgG & In serum & In feces & \\
\hline TH-hu-FJN & + & ND & - & + & + & MH427099 \\
TH-hu-FNP & + & + & + & + & MH427105 \\
TH-hu-FYS & + & + & - & + & MH427098 \\
TH-hu-FUD & + & + & - & + & MH427100 \\
TH-hu-FKP & + & + & + & + & MH427106 \\
TH-hu-FSN & + & + & + & + & MH427095 \\
TH-hu-FOG & + & + & + & + & MH427103 \\
TH-hu-FTM & + & ND & + & + & MH427096 \\
TH-hu-FLR & + & + & - & + & MH427104 \\
TH-hu-F40 & + & + & + & + & MH427091 \\
TH-hu-FPP & - & + & + & + & MH427092 \\
TH-hu-FKS & + & + & + & + & MH427090 \\
TH-hu-FSP & + & ND & + & + & MH427097 \\
TH-hu-F45-1 & + & ND & + & + & KY232312, \\
TH-hu-FTK & + & + & - & + & MH427094 \\
TH-hu-FTS & + & + & + & + & MH427102 \\
TH-hu-FVS & + & + & + & + & MH427093 \\
TH-hu-F47 & + & + & + & + & MH427101 \\
\hline
\end{tabular}

The anti-HEV, both IgM and IgG, were detected in the serum specimens. The HEV RNA was detected from serum and fecal samples. HEV in the serum and fecal specimens from patient TH-hu-F45-1 was chosen to perform genome sequencing. The accession number KY232312 and KY232313 refer to the HEV from serum and feces, respectively

$N D$ not done

for the reverse-transcription PCR of the HEV capsid gene in feces. Of those 18 fecal HEV-positive patients, only 13 (72.2\% of 18 people) had the HEV RNA detectable in their serum (Table 2). This result suggests that the detection of HEV RNA in feces has more potential than it does through serum.

\section{Phylogenetic-based HEV genotype identification}

We performed the Sanger's sequencing of the partial capsid gene, which was located on the open reading frame 2 (ORF2) of the HEV genome, from the 19 reverse transcription PCR positive amplicons, but from $18 \mathrm{HEV}$ patients. That was because the patient "TH-hu- 45 " had reverse transcription PCR positive in both serum and fecal samples. So, the 19 capsid sequences from the Thai HEV and the other $43 \mathrm{HEV}$ from the other study [18] were then aligned and trimmed the incomplete sequence regions at both ends of the multiple sequence alignment (MSA). The alignment matrix of 566 characters $\times 63$ taxa was subjected to the molecular phylogenetic analyses using the maximum likelihood (ML) and Bayesian Inference (BI) methods. The tree topologies between the ML and the BI phylogenies were almost identical. The conflict topology was presented in the clade of FJ906895 and KJ013415, which appeared to be the sister clade of the genotype 3 in the ML tree. The Bayesian phylogeny of these sequences illustrated at least five monophyletic clades correlated with the HEV genotypes (Fig. 1). The HEV genotypes 3 was appeared to be the sister clade of the remaining genotype (e.g., genotype 1, 2, 4, 5, 6, and 7). The HEV non-genotype 3 were clustered in a monophyletic group with two subclades. The former showed a cluster of the genotypes 4,5 , and 6 . The single taxon belonging to genotype 5 was the sister taxon of genotype 6 , and genotype 5 and 6 were the sister clade of genotype 4 (Fig. 1). The latter illustrated the cluster of HEV genotypes 1,2, and 7. The single taxon of genotype 2 was a sister taxon of genotype 1, and they were sister clades of HEV genotype 7 (Fig. 1).

All 19 Thai isolates of HEV were identified as the HEV genotype 3 (Fig. 1). The HEV genotype 3 appeared to be the largest monophyletic clade of HEV. This clade was further separated into two subclades; subclade 3.1 and subclade 3.2. Interestingly, the Thai isolates of HEV were present in both subclade 3.1 and 3.2. Seventeen sequences were identified as being in the subgenotype 3.1, whereas the other two sequences belonged to the subgenotype 3.2. There were three monophyletic groups of nucleotide sequences of the Thai isolates of HEV in the subgenotype 3.1: (i) the first clade was comprised of seven sequences, including $\mathrm{TH}-$ hu-F40, TH-hu-FPP, TH-hu-FLR, TH-hu-S45-1, TH-huF45-1, TH-hu-FKS, and TH-hu-FSP; (ii) the second clade was comprised of eight sequences, including TH-hu-FJN, TH-hu-FNP, TH-hu-FYS, TH-hu-FOG, TH-hu-FTM, THhu-FUD, TH-hu-FKP, and TH-hu-FSN; and (iii) the third clade was comprised of two sequences, TH-hu-FTK and THhu-FTS (Fig. 1). The two nucleotide sequences, TH-hu-F47 and TH-hu-FVS, in the subgenotype 3.2 formed paraphyletic relationship on the tree (Fig. 1).

\section{Genome sequences of the Thai isolates of HEV}

We attempted to sequence the HEV genome from all HEVpositive patients, but, unfortunately, only two samples from one patient (TH-hu-45) had enough RNA to perform the genome sequencing of HEV. The serum and fecal samples were then sequenced along the entire coding regions (a nearly complete genome) by direct sequencing of the 12 amplified fragments along the HEV genome. After these were manually assembled, we derived two scaffold genomes. One was the HEV isolate TH-hu-S45-1 (accession number KY232312), which derived from a serum sample, and the other was TH-hu-F45-1 (accession number KY232313), the HEV from the fecal sample. The genome size of these two 


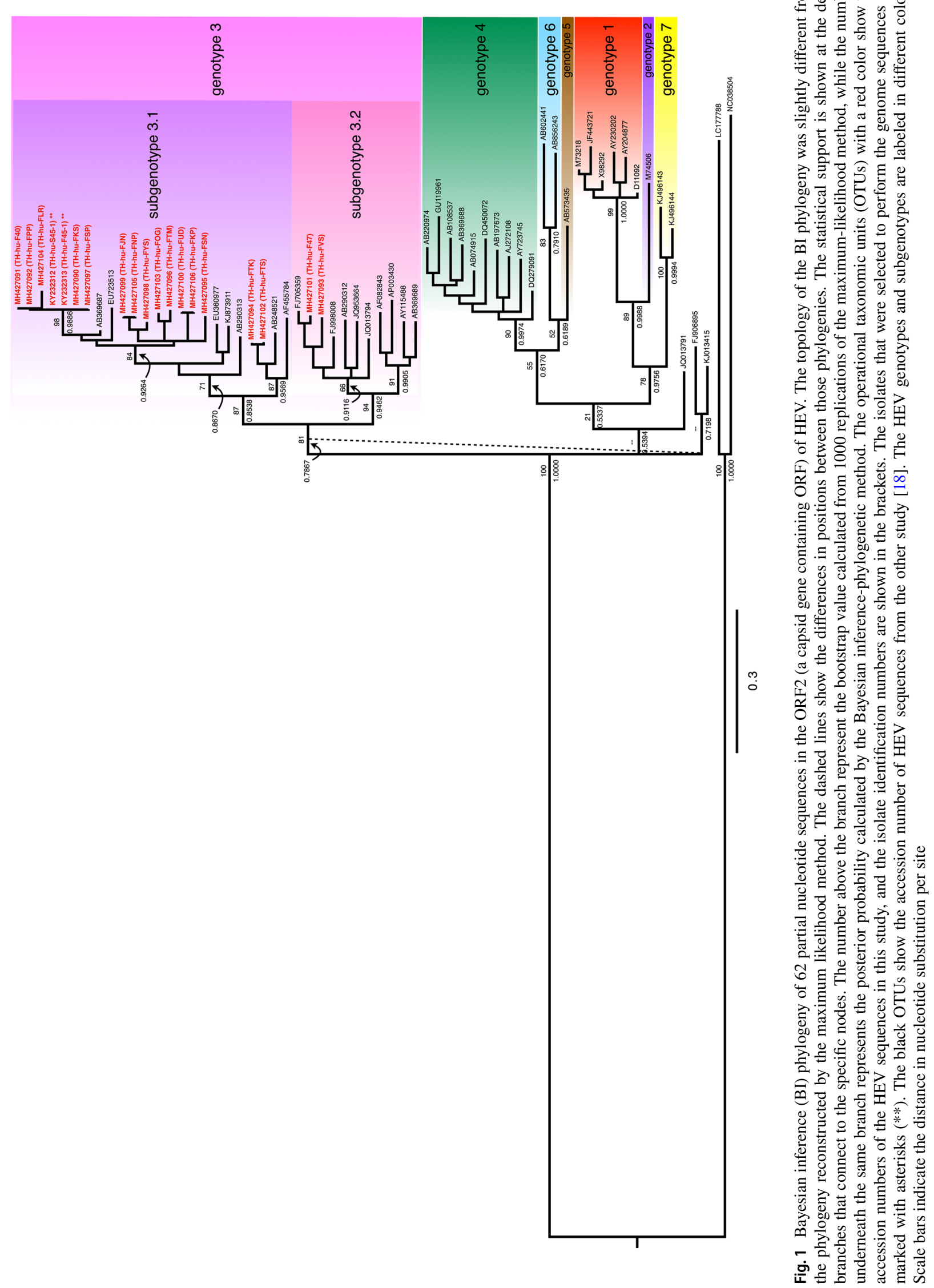


isolates appeared to be the same size of 7235 nucleotides in length (Fig. 2a).

Both genomes were comprised three open reading frames (ORFs). The ORF1 had 5115 nucleotides in length (position 11-5125 in the genome sequence), which was encoded for a polyprotein that was cleaved into eight polypeptides, starting from a viral methyltransferase enzyme; a Y domain; a papain-like cysteine protease; a hypervariable region; a proline-rich region; a protein with unknown function; a helicase; and an RNA-dependent RNA polymerase (Fig. 2a). The ORF2 had 1983 nucleotides in length at position 5160-7142, which located at the 3'-terminal of the genome. This region was coded for 660 amino acid residues of the viral capsid protein. The ORF3 was the smallest ORF that overlapped with the ORF1 and ORF2 on the HEV genome (Fig. 2a). It contained 369 nucleotides at the position 5122-5490, and was coded for a protein with an unknown function.

Genome comparisons between the HEV isolated from serum and feces showed $99.8 \%$ similarity among nucleotide sequences and $99.9 \%$ identity of the amino acid sequences. The total of ten nucleotide-substitutions occurred between these two isolates of HEV. Seven of ten substitutions were detected on the ORF1, while the other three positions were detected on the ORF2 (Fig. 2b). In the ORF1, three synonymous substitutions occurred in the viral methyltransferase gene (positions 151, 175, and 178), two synonymous substitutions occurred in the protease gene (positions 1498 and 1507), and one synonymous substitution occurred in the proline-rich protein (position 2245). Only one mutation at the position 4088 was identified as a non-synonymous substitution, which was presented as histidine $(\mathrm{H})$ in the HEV isolated from serum, but as tyrosine (Y) in the HEV isolated from feces of the same patient. The other three synonymous substitutions (positions 5594, 5678, and 6248) were found on the capsid protein (ORF2). There was no nucleotide substitution detected on the ORF3.

\section{Genome-scale phylogeny of HEV}

Phylogenetic reconstruction of two HEV genome sequences isolated from a Thai patient and the 95 genome sequences from the other studies were performed using the ML and BI methods. Tree topologies at the deep branching of the ML and BI phylogenies were identical (Fig. 3). Obviously, the genome phylogenies clustered HEV by the genotypic patterns of the HEV. Comparisons between the genome and the ORF2 phylogenies illustrated three

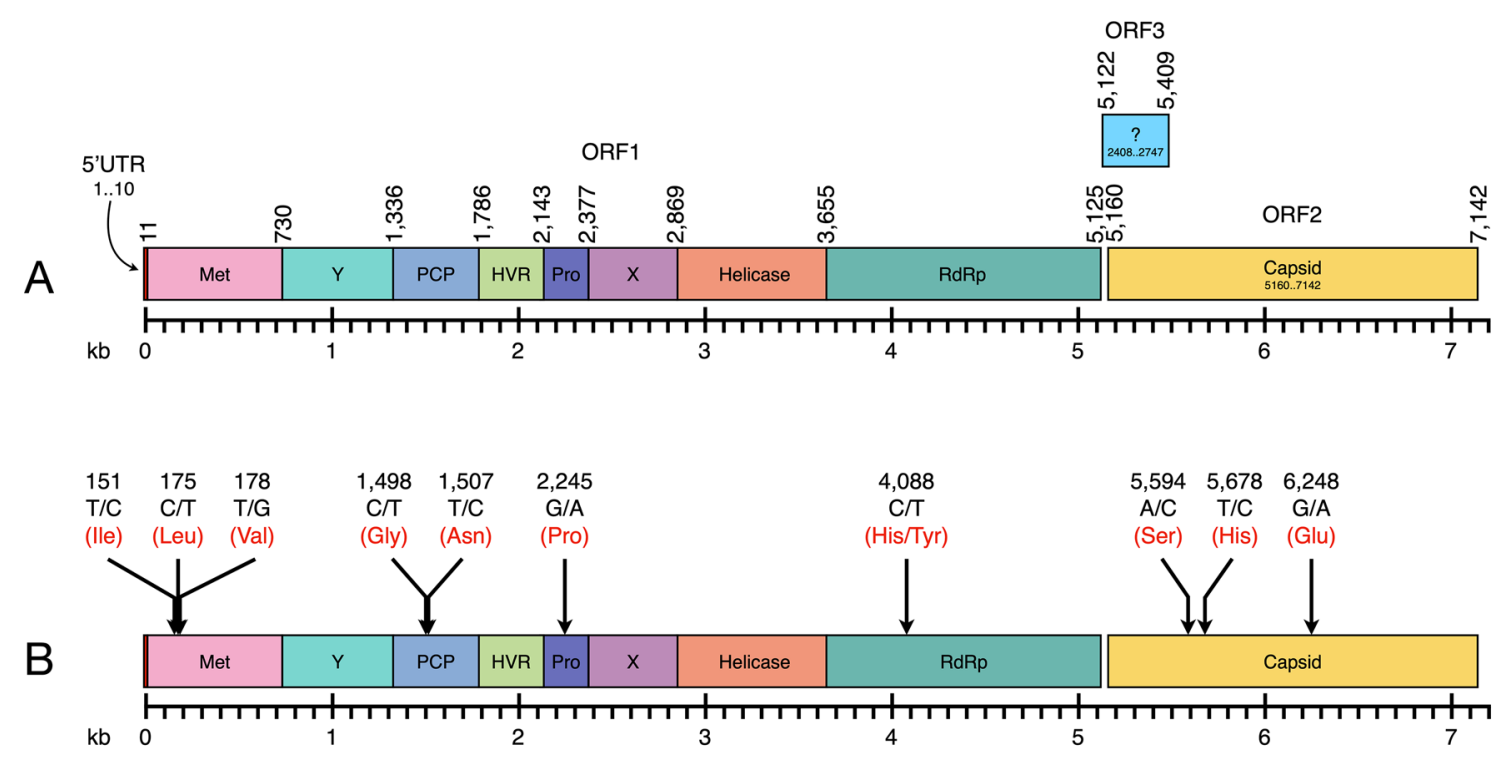

Fig. 2 Genome organization of the Thai isolates of HEV (KY232312 and KY232313) and mutation events between those two genomes: the HEV genomes from serum and feces were identical in size and organization (a). The total length of the HEV genomes was 7142 bp, organized in three ORFs-1, 2, and 3. The ORF1 encoded a nonstructural polyprotein which contained at least eight regions, including a methyltransferase (Met), a Y domain (Y), a papain-like cysteine protease (PCP), a hypervariable region (HVR), a proline-rich region (Pro), a protein with an unknown function (X), a helicase (Helicase), and an RNA-dependent RNA polymerase (RdRp). The ORF2 encoded a single capsid gene (Capsid), and the ORF3 also carried a single pro- tein with unknown function. The numbers on the genome diagram represent the boundary of each protein in the genome. Nucleotide substitution sites on the two genomes are shown by arrows and are labeled in black numbers (b). The labels at each arrow tail represent the nucleotide substitution site, pattern of nucleotide-substitution, and amino acid. The nucleotide in the HEV genome isolated from serum (KY232312), and feces (KY232313) are separated by a slash (/). The amino acids encoded from the mutation position are shown in red. Regarding the non-synonymous substitution, the amino acids in the different genomes are separated by a slash (/) 


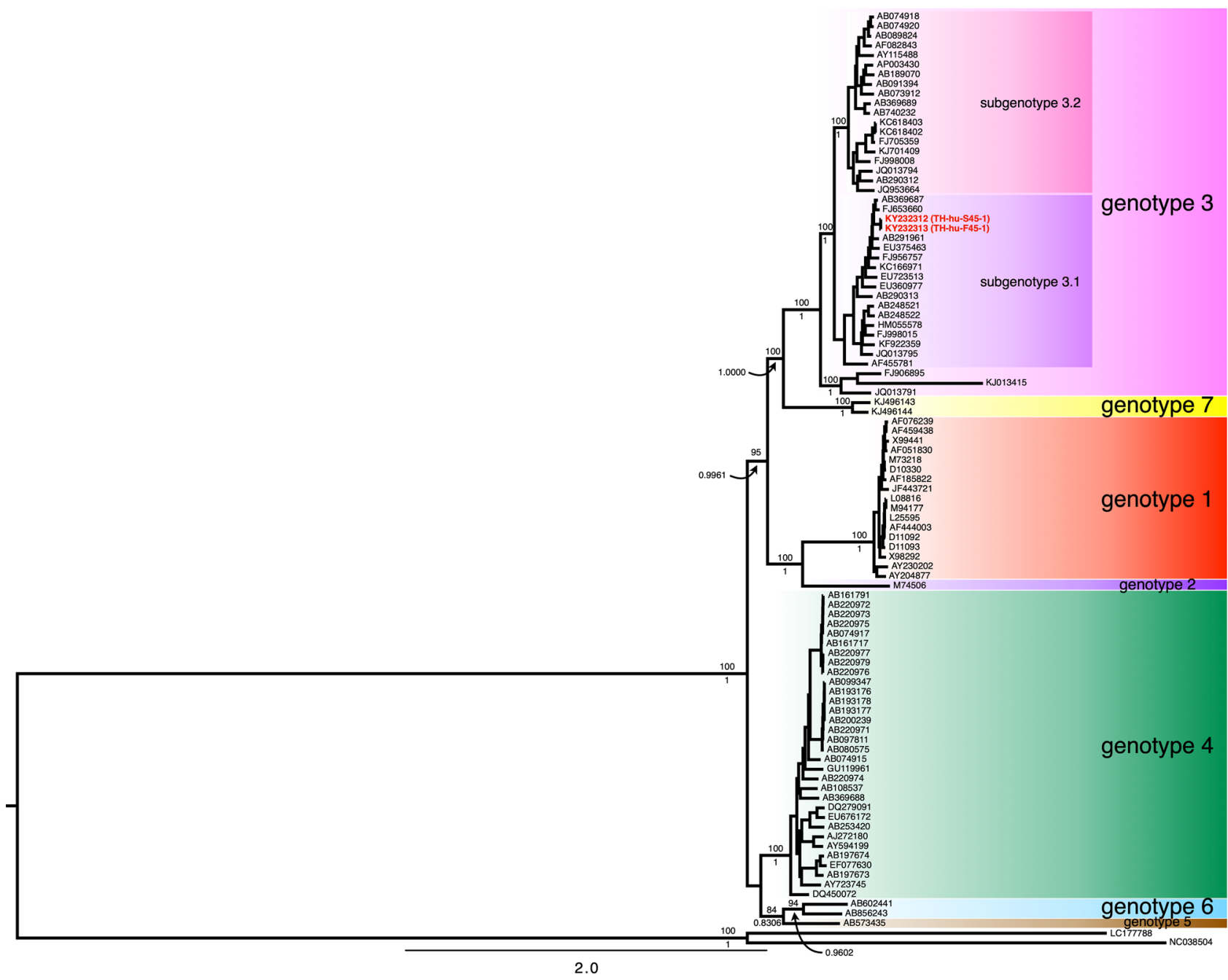

Fig. 3 The Bayesian inference (BI) phylogeny of 97 partial genome sequences of HEV, including the two isolates from this study. The phylogenetic analyses were reconstructed by ML and BI methods. The tree topologies were identical between both the ML and BI phylogenies. Statistical supports of the branches are shown on the deep branches. The number above the branch represents the bootstrap value calculated from 1000 replications of the maximum-likelihood method, while the number underneath the same branch represents the

different points. First, the basal split separated HEV into two major clades, which contained the HEV genotypes 4,5 , and 6 in one clade and the remaining genotypes in another clade (Fig. 3). However, the basal split in the ORF2 phylogeny appeared to be the polytomy of three clades, including (i) the HEV genotype 3, (ii) the unclassified HEV genotype 3 (FJ906895 and KJ013415) isolated from rabbits, and (iii) the remaining HEV genotypes and JQ013791-an isolate of HEV genotype 3 (Fig. 1). Second, HEV genotype 3 formed a monophyletic group in the genome phylogeny (Fig. 3), but polyphyletic in the ORF2 phylogeny (Fig. 1). That is because the three HEV isolated from rabbits (FJ906895, KJ013415, and JQ013791) were posterior probability calculated by the Bayesian inference phylogenetic method. The OTUs in red show the accession numbers of the HEV genome sequences in this study, and the isolate identification numbers are shown in brackets, whereas the OTUs in black show the accession number of HEV sequences from the other study [15, 24 73]. The HEV genotypes and subgenotypes are labeled with differentcolored boxes. Scale bars indicate the distance in nucleotide substitutions per site

excluded from the HEV genotype 3 clade. Nevertheless, in the ORF2 phylogeny, the sequences of HEV genotype 3 isolated from human formed a monophyletic group, but the branching positions of the HEV sequences isolated from rabbits were incongruence between the ML and BI phylogenies (Fig. 1). Third, the genotype 3 clade in both genome and ORF2 phylogenies was split into two subgenotypes, called 3.1 and 3.2. These revealed exhibited that the ORF2 phylogeny had low phylogenetic discriminatory power for HEV genotyping than the genome phylogeny, particularly for the HEV genotype 3. Therefore, the phylogenetic identification of HEV genotypes based on the genome-scale data can be more reliable than the power of the partial 
ORF2 sequences. Both Thai isolates of HEV were identified as HEV genotype 3, subgenotype 3.1 (Fig. 3).

\section{Discussion}

We detected HEV RNA from 18 fecal specimens from a total of 20 Thai patients, who developed IgM or IgG against HEV from 2014 to 2016 (Table 2). All 18 HEV RNA-positive samples were then sequenced for partial ORF2 region (919 bp), which encoded a part of viral capsid protein. The phylogenetic analysis revealed that all Thai isolates of HEV belonged to the HEV genotype 3 (Fig. 1, 3). The HEV genotype 3 was further divided into two subgenotypes, 3.1 and 3.2. Only two isolates of the HEV in this study were identified as subgenotype 3.2, whereas the other isolates belonged to the subgenotype 3.1 (Fig. 1). Only one HEV patient had enough concentration of RNA in the fecal and serum specimens for performing whole genome sequencing. Therefore, only two HEV genomes were successfully sequenced from the serum (KY232312) and feces (KY232313) of the same patient. Both HEV genomes illustrated high similarity to the typical HEV genome (Fig. 2a). However, there were ten nucleotide substitutions found in both genomes. A single non-synonymous substitution occurred at position 4088, while the other nine synonymous substitutions were detected along the genome (Fig. 2b). Both Thai HEV genome were identified as the HEV genotype 3, and the subgenotype 3.1 (Fig. 3). The genome tree appeared to have more phylogenetically informative than the ORF2 phylogeny at least for HEV genotype identification and because of the monophyly of the genotype 3 (Figs. 1, 3).

The immunological diagnosis for confirming acute HEV infection typically relies on the presence of IgM. In our study, we found IgM in all patients' sera except for one individual who was immunocompromised because of solid organ transplantation. So, the negative result for IgM from the detection might have been affected of either the sensitivity of the test or the host's immunological weakness due to the immunosuppressive drug [4, 74]. The efficiency of HEV RNA detection in feces $(90 \%$; 18 of 20 samples) was better than in serum ( $65 \%$; 13 of 20 samples). This observation is similar to that involving HEV RNA detection in the other study [75].

\section{HEV genotyping using the ORF2 phylogeny}

Using only $900 \mathrm{bp}$ of the capsid protein sequences might not involve enough phylogenetic signals for HEV systematics and evolution. This is because the mutations occurred randomly throughout the HEV genome [76, 77], and the tree reconstructed from the short sequences probably conflicted with the genome tree. The ORF2 phylogenies reconstructed from the ML and BI methods revealed the conflict topology against the genome phylogeny. This confirmed that the phylogenetic characters used in the dataset (568 bp after truncation of the unwanted regions) have less power for resolving HEV's systematic and evolution. However, the sequences are adequate for most of HEV genotype identification. HEV in each genotype were part of the monophyletic group except the genotype 3, which were not cluster the HEV isolated from rabbits within the clade of HEV genotype 3 .

\section{HEV genotype 3}

The genome phylogeny demonstrated that the monophyly of the HEV genotype 3 (Fig. 3). Within the genotype 3 clade, the HEV isolated from the non-human hosts (FJ906895, KJ013415, and JQ013791) were separated from the HEV genotype 3 that isolated from humans. The HEV isolated from human hosts was further split into two subclades, called the subgenotype 3.1 and 3.2 (Fig. 3). This branching pattern was also observed in the ORF2 phylogeny (Fig. 1). The Thai isolates of HEV appeared to be the genotype 3, especially the subgenotype 3.1 (16 of 18 isolates). However, the HEV genotype 3.2 was less frequently found among Thai population than the subgenotype 3.1 ( 2 of 18 isolates).

In comparisons using the current genotyping system [18], the subgenotype 3.1 gathered the genotypes $3 \mathrm{e}$ (AB248521), 3f (AB369687), and 3g (AF455784) within the clade. Contrary to the 3.1, HEV genotype 3.2 seems to have more genetic diversity. It contains the genotypes $3 \mathrm{a}$ (AF082843), 3b (AP003430), 3c (FJ705359), 3h (JQ013794), 3i (FJ998008), 3j (AY115488), 3k (AB369689), and 31 (JQ953664) in the tree $[18,78]$.

In conclusion, the HEV-genome based genotyping of the 18 Thai patients showed that they belonged to the genotype 3. Majority of those isolates belonged to the subgenotype 3.1 , while a couple of isolates belonged to the subgenotypes 3.2. We also provided two HEV genomes from Thailand. The greater number of HEV genomes allows for explorations of mutations in the other ORFs. Improvement of the molecular phylogenetic systematics will enhance the accuracy of the HEV genotyping and evolution. Our knowledge from the tree can also apply to manipulating the HEV in public health and to providing the necessary information in molecular epidemiology for the prevention of HEV outbreaks.

Acknowledgements The authors gratefully acknowledge the patients who donated blood and stool for use in this study. This study was supported by the Siriraj Research Fund, Faculty of Medicine Siriraj Hospital, Mahidol University, Bangkok, Thailand (Grant No. R015932031). TC was supported by Siriraj Graduate Scholarship for her study.

Author contributions SL and PW conceived and designed the study and all the experiments. TP and PW performed the experiments and collected all data. WC and SC provided the samples and clinical 
investigation. TP, PA, and PW analyzed the data. TP and SL wrote the manuscript. PA and PW edited the manuscript, figures, and tables. All authors read and approved the final manuscript.

\section{Compliance with ethical standards}

Conflict of interest The authors declare that there are no conflicts of interest.

Ethical approval The ethics committee approved this study for research in humans at the Faculty of Medicine Siriraj Hospital, Mahidol University, Bangkok, Thailand (IRB No. Si 699/2014).

Open Access This article is licensed under a Creative Commons Attribution 4.0 International License, which permits use, sharing, adaptation, distribution and reproduction in any medium or format, as long as you give appropriate credit to the original author(s) and the source, provide a link to the Creative Commons licence, and indicate if changes were made. The images or other third party material in this article are included in the article's Creative Commons licence, unless indicated otherwise in a credit line to the material. If material is not included in the article's Creative Commons licence and your intended use is not permitted by statutory regulation or exceeds the permitted use, you will need to obtain permission directly from the copyright holder. To view a copy of this licence, visit http://creativecommons.org/licenses/by/4.0/.

\section{References}

1. Teshale EH, Hu DJ (2011) Hepatitis E: epidemiology and prevention. World J Hepatol 3(12):285-291

2. Kamar N, Selves J, Mansuy J-M, Ouezzani L, Péron J-M, Guitard J, Cointault O, Esposito L, Abravanel F, Danjoux M, Durand D, Vinel J-P, Izopet J, Rostaing L (2008) Hepatitis E virus and chronic hepatitis in organ-transplant recipients. N Engl J Med 358:811-818

3. Sayed IM, Vercouter A-S, Abdelwahab SF, Vercauteren K, Meuleman $P$ (2015) Is hepatitis $E$ virus an emerging problem in industrialized countries? Hepatology 62(6):1883-1892

4. Al-Sadeq DW, Majdalawieh AF, Mesleh AG, Abdalla OM, Nasrallah GK (2018) Laboratory challenges in the diagnosis of hepatitis E virus. J Med Microbiol 67(4):466-480

5. Purdy MA, Harrison TJ, Jameel S, Meng X-J, Okamoto H, Van der Poel WHM, Smith DB, ICTV Report Consortium (2017) ICTV virus taxonomy profile: Hepeviridae. J Gen Virol 98:2645-2646

6. Kamar N, Izopet J, Pavio N, Aggarwal R, Labrique A, Heiner H, Dalton HR (2017) Hepatitis E virus infection. Nat Rev Dis Primers 3:17086

7. Liu P, Li L, Wang L, Bu Q, Fu H, Han J, Zhu Y, Lu F, Zhuang $H$ (2012) Phylogenetic analysis of 626 hepatitis E virus (HEV) isolates from humans and animals in China (1986-2011) showing genotype diversity and zoonotic transmission. Infect Genet Evol 12:428-434

8. Pavio N, Meng X-J, Doceul V (2015) Zoonotic origin of hepatitis E. Curr Opin Virol 10:34-41

9. Okamoto H (2007) Genetic variability and evolution of hepatitis E virus. Virus Res 127:216-228

10. Forni D, Cagliani R, Clerici M, Sironi M (2018) Origin and dispersal of Hepatitis E virus. Emerg Microbes Infect 7:11

11. Choi JY, Lee J-M, Jo YW, Min HJ, Kim HJ, Jung WT, Lee OJ, Yun H, Yoon Y-S (2013) Genotype-4 hepatitis E in a human after ingesting roe deer meat in South Korea. Clin Mol Hepatol 19(3):309-314

12. Tsoi W-C, Zhu X, To AP-C, Holmberg J (2020) Hepatitis E virus infection in Hong Kong blood donors. Vox Sang 115:11-17

13. Wang B, Akanbi OA, Harms D, Adesina O, Osundare FA, Naidoo D, Deveaux I, Ogundiran O, Ugochukwu U, Mba N, Ihekweazu C, Bock C-T (2017) A new hepatitis E virus genotype 2 strain identified from an outbreak in Nigeria. Virol J 15:163

14. Suwannakarn K, Tongmee C, Theamboonlers A, Komolmit P, Poovorawan Y (2010) Swine as the possible source of hepatitis E virus transmission to humans in Thailand. Adv Virol 155:1697-1699

15. Siripanyaphinyo U, Laohasinnarong D, Siripanee J, Kaeoket K, Kameoka M, Ikuta K, Sawanpanyalert P (2009) Full-length sequence of genotype 3 hepatitis $\mathrm{E}$ virus derived from a pig in Thailand. J Med Virol 81(4):657-664

16. Namsai A, Louisirirotchanakul S, Wongchinda N, Siripanyaphinyo U, Virulhakul P, Puthavathana P, Myint KS, Gannarong M, Ittapong R (2011) Surveillance of hepatitis A and E viruses contamination in shellfish in Thailand. Lett Appl Microbiol 53(6):608-613

17. Gouy M, Guindon S, Gascuel O (2010) SeaView version 4: a multiplatform graphical user interface for sequence alignment and phylogenetic tree building. Mol Biol Evol 27(2):221-224

18. Smith DB, Simmonds P, Izopet J, Oliveira-Filho EF, Ulrich RG, Johne R, Koenig M, Jameel S, Harrison TJ, Meng X-J, Okamoto H, Van der Poel WHM, Purdy MA (2016) Proposed reference sequences for hepatitis E virus subtypes. J Gen Virol 97(Pt 3):537-542

19. Edgar RC (2004a) MUSCLE: multiple sequence alignment with high accuracy and high throughput. Nucleic Acids Res 32(5):1792-1797

20. Edgar RC (2004b) MUSCLE: a multiple sequence alignment method with reduced time and space complexity. BMC Bioinform 5:113

21. Guindon S, Dufayard JF, Lefort V, Anisimova M, Hordijk W, Gascuel O (2010) New algorithms and methods to estimate maximum-likelihood phylogenies: assessing the performance of PhyML 3.0. Syst Biol 59(3):307-321

22. Ronquist F, Teslenko M, van der Mark P, Ayres DL, Darling A, Höhna S, Larget B, Liu L, Suchard MA, Huelsenbeck JP (2012) MRBAYES 3.2: Efficient Bayesian phylogenetic inference and model selection across a large model space. Syst Biol 61:539-542

23. Rambaut A. (2014) FigTree v1.4.2, A graphical viewer of phylogenetic trees. https://tree.bio.ed.ac.uk/software/figtree/

24. Adlhoch C, Wolf A, Meisel H, Kaiser M, Ellerbrok H, Pauli G (2009) High HEV presence in four different wild boar populations in East and West Germany. Vet Microbiol 139:270-278

25. Adlhoch C, Kaiser M, Pauli G, Koch J, Meisel H (2009) Indigenous hepatitis $\mathrm{E}$ virus infection of a plasma donor in Germany. Vox Sang 97:303-308

26. Aye TT, Uchida T, Ma XZ, Iida F, Shikata T, Zhuang H, Win KM (1992) Complete nucleotide sequence of a hepatitis $\mathrm{E}$ virus isolated from the Xinjiang epidemic (1986-1988) of China. Nucleic Acids Res 20:3512

27. Bi SL, Purdy MA, McCaustland KA, Margolis HS, Bradley DW (1993) The sequence of hepatitis E virus isolated directly from a single source during an outbreak in China. Virus Res 28:233-247

28. Bouquet J, Cherel P, Pavio N (2012) Genetic characterization and codon usage bias of full-length Hepatitis E virus sequences shed new lights on genotypic distribution, host restriction and genome evolution. Infect Genet Evol 12:1842-1853

29. Chobe LP, Lole KS, Arankalle VA (2006) Full genome sequence and analysis of Indian swine hepatitis $\mathrm{E}$ virus isolate of genotype 4. Vet Microbiol 114:240-251 
30. Donati MC, Fagan EA, Harrison TJ (1997) Sequence analysis of full length HEV clones derived directly from human liver in fulminant hepatitis E. In: Rizzetto M, Purcell RH, Gerin JL, Verme G (eds) Viral hepatitis and liver disease. Edizioni Minerva Medica, Torino, pp 313-316

31. Emerson SU, Zhang M, Meng XJ, Nguyen H, St Claire M, Govindarajan S, Huang YK, Purcell RH (2001) Recombinant hepatitis $\mathrm{E}$ virus genomes infectious for primates: importance of capping and discovery of a cis-reactive element. Proc Natl Acad Sci USA 98:15270-15275

32. Fu H, Wang L, Zhu Y, Geng J, Li L, Wang X, Bu Q, Zhuang H (2011) Analysing complete genome sequence of swine hepatitis E virus (HEV), strain CHN-XJ-SW13 isolated from Xinjiang, China: putative host range, and disease severity determinants in HEV. Infect Genet Evol 11:618-623

33. Gouvea V, Snellings N, Popek MJ, Longer CF, Innis BL (1998) Hepatitis E virus: complete genome sequence and phylogenetic analysis of a Nepali isolate. Virus Res 57:21-26

34. Huang CC, Nguyen D, Fernandez J, Yun KY, Fry KE, Bradley DW, Tam AW, Reyes GR (1992) Molecular cloning and sequencing of the Mexico isolate of hepatitis E virus (HEV). Virology 191:550-558

35. Inoue J, Nishizawa T, Takahashi M, Aikawa T, Mizuo H, Suzuki K, Shimosegawa T, Okamoto H (2006) Analysis of the fulllength genome of genotype 4 hepatitis $\mathrm{E}$ virus isolates from patients with fulminant or acute self-limited hepatitis E. J Med Virol 78:476-484

36. Inoue $\mathrm{J}$, Takahashi $\mathrm{M}$, Ito $\mathrm{K}$, Shimosegawa $\mathrm{T}$, Okamoto $\mathrm{H}$ (2006) Analysis of human and swine hepatitis E virus (HEV) isolates of genotype 3 in Japan that are only $81-83 \%$ similar to reported HEV isolates of the same genotype over the entire genome. J Gen Virol 87:2363-2369

37. Izopet J, Dubois M, Bertagnoli S, Lhomme S, Marchandeau S, Boucher S, Kamar N, Abravanel F, Guerin JL (2012) Hepatitis e virus strains in rabbits and evidence of a closely related strain in humans, France. Emerg Infect Dis 18:1274-1281

38. Jameel S, Zafrullah M, Chawla YK, Dilawari JB (2002) Reevaluation of a North India isolate of hepatitis E virus based on the full-length genomic sequence obtained following long RT-PCR. Virus Res 86:53-58

39. Johne R, Reetz J, Ulrich RG, Machnowska P, Sachsenroder J, Nickel P, Hofmann J (2014) An ORF1-rearranged hepatitis E virus derived from a chronically infected patient efficiently replicates in cell culture. J Viral Hepatitis 21:447-456

40. Kuno A, Ido K, Isoda N, Satoh Y, Ono K, Satoh S, Inamori H, Sugano K, Kanai N, Nishizawa T, Okamoto H (2003) Sporadic acute hepatitis $\mathrm{E}$ of a 47 -year-old man whose pet cat was positive for antibody to hepatitis E virus. Hepatol Res 26:237-242

41. Lhomme S, Abravanel F, Dubois M, Sandres-Saune K, Mansuy JM, Rostaing L, Kamar N, Izopet J (2014) Characterization of the polyproline region of the hepatitis $\mathrm{E}$ virus in immunocompromised patients. J Virol 88:12017-12025

42. Liu Z, Chi B, Takahashi K, Mishiro S (2003) A genotype IV hepatitis $\mathrm{E}$ virus strain that may be indigenous to Changchun, China. Intervirology 46:252-256

43. Lorenzo FR, Tsatsralt-Od B, Ganbat S, Takahashi M, Okamoto H (2007) Analysis of the full-length genome of hepatitis E virus isolates obtained from farm pigs in Mongolia. J Med Virol 79:1128-1137

44. Meng XJ, Purcell RH, Halbur PG, Lehman JR, Webb DM, Tsareva TS, Haynes JS, Thacker BJ, Emerson SU (1997) A novel virus in swine is closely related to the human hepatitis $\mathrm{E}$ virus. Proc Natl Acad Sci USA 94:9860-9865

45. Mishra N, Walimbe AM, Arankalle VA (2013) Hepatitis E virus from India exhibits significant amino acid mutations in fulminant hepatic failure patients. Virus Genes 46:47-53
46. Moal V, Ferretti A, Devichi P, Colson P (2014) Genome sequence of a hepatitis $\mathrm{E}$ virus of genotype $3 \mathrm{e}$ from a chronically infected kidney transplant recipient. Genome Announc 2(1):e01156-e1213

47. Moal V, Gerolami R, Ferretti A, Purgus R, Devichi P, Burtey S, Colson P (2014) Hepatitis E irus of subtype $3 i$ in chronically infected kidney transplant recipients in southeastern France. J Clin Microbiol 52:3967-3972

48. Nishizawa T, Takahashi M, Mizuo H, Miyajima H, Gotanda Y, Okamoto H (2003) Characterization of Japanese swine and human hepatitis $\mathrm{E}$ virus isolates of genotype IV with $99 \%$ identity over the entire genome. J Gen Virol 84:1245-1251

49. Obermiller LE, Pfeiler E (2003) Phylogenetic relationships of elopomorph fishes inferred from mitochondrial ribosomal DNA sequences. Mol Phylogenet Evol 26:202-214

50. Okamoto H, Takahashi M, Nishizawa T, Fukai K, Muramatsu U, Yoshikawa A (2001) Analysis of the complete genome of indigenous swine hepatitis E virus isolated in Japan. Biochem Biophys Res Commun 289:929-936

51. Panda SK, Ansari IH, Durgapal H, Agrawal S, Jameel S (2000) The in vitro-synthesized RNA from a cDNA clone of hepatitis $\mathrm{E}$ virus is infectious. J Virol 74:2430-2437

52. Pei Y, Yoo D (2002) Genetic characterization and sequence heterogeneity of a Canadian isolate of Swine hepatitis E virus. J Clin Microbiol 40:4021-4029

53. Peralta B, Mateu E, Casas M, de Deus N, Martin M, Pina S (2009) Genetic characterization of the complete coding regions of genotype 3 hepatitis E virus isolated from Spanish swine herds. Virus Res 139:111-116

54. Schielke A, Sachs K, Lierz M, Appel B, Jansen A, Johne R (2009) Detection of hepatitis $\mathrm{E}$ virus in wild boars of rural and urban regions in Germany and whole genome characterization of an endemic strain. Virol J 6:58

55. Shiota T, Li TC, Yoshizaki S, Kato T, Wakita T, Ishii K (2013) The hepatitis e virus capsid C-terminal region is essential for the viral life cycle: implication for viral genome encapsidation and particle stabilization. J Virol 87:6031-6036

56. Takahashi K, Iwata K, Watanabe N, Hatahara T, Ohta Y, Baba K, Mishiro S (2001) Full-genome nucleotide sequence of a hepatitis E virus strain that may be indigenous to Japan. Virology 287:9-12

57. Takahashi K, Kang JH, Ohnishi S, Hino K, Mishiro S (2002) Genetic heterogeneity of hepatitis E virus recovered from Japanese patients with acute sporadic hepatitis. J Infect Dis 185:1342-1345

58. Takahashi K, Kang JH, Ohnishi S, Hino K, Miyakawa H, Miyakawa Y, Maekubo H, Mishiro S (2003) Full-length sequences of six hepatitis E virus isolates of genotypes III and IV from patients with sporadic acute or fulminant hepatitis in Japan. Intervirology 46:308-318

59. Takahashi K, Kitajima N, Abe N, Mishiro S (2004) Complete or near-complete nucleotide sequences of hepatitis $\mathrm{E}$ virus genome recovered from a wild boar, a deer, and four patients who ate the deer. Virology 330:501-505

60. Takahashi K, Okada K, Kang J, Karino Y, Ichida T, Matsuda H, Ohnishi S, Toyota J, Yamagiwa S, Maekubo H, Abe N, Mishiro S (2005) A lineage of hepatitis E virus within genotype IV, associated with severe forms of hepatitis. Kanzo 46:389-390

61. Takahashi K, Terada S, Kokuryu H, Arai M, Mishiro S (2010) A wild boar-derived hepatitis $\mathrm{E}$ virus isolate presumably representing so far unidentified 'genotype 5. Kanzo 51:536-538

62. Takahashi K, Toyota J, Karino Y, Kang JH, Maekubo H, Abe N, Mishiro S (2004) Estimation of the mutation rate of hepatitis E virus based on a set of closely related 7.5-year-apart isolates from Sapporo. Jpn Hepatol Res 29:212-215

63. Takahashi M, Nishizawa T, Nagashima S, Jirintai S, Kawakami M, Sonoda Y, Suzuki T, Yamamoto S, Shigemoto K, Ashida K, Sato Y, Okamoto H (2013) Molecular characterization of a novel 
hepatitis E virus (HEV) strain obtained from a wild boar in Japan that is highly divergent from the previously recognized HEV strains. Virus Res 180:59-69

64. Takahashi M, Nishizawa T, Sato H, Sato Y, Jirintai NS, Okamoto $\mathrm{H}$ (2011) Analysis of the full-length genome of a hepatitis $\mathrm{E}$ virus isolate obtained from a wild boar in Japan that is classifiable into a novel genotype. J Gen Virol 92:902-908

65. Takahashi M, Nishizawa T, Yoshikawa A, Sato S, Isoda N, Ido K, Sugano K, Okamoto H (2002) Identification of two distinct genotypes of hepatitis $\mathrm{E}$ virus in a Japanese patient with acute hepatitis who had not travelled abroad. J Gen Virol 83:1931-1940

66. Tam AW, Smith MM, Guerra ME, Huang CC, Bradley DW, Fry KE, Reyes GR (1991) Hepatitis E virus (HEV): molecular cloning and sequencing of the full-length viral genome. Virology 185:120-131

67. Tokita H, Harada H, Gotanda Y, Takahashi M, Nishizawa T, Okamoto H (2003) Molecular and serological characterization of sporadic acute hepatitis $E$ in a Japanese patient infected with a genotype III hepatitis E virus in 1993. J Gen Virol 84:421-427

68. van Cuyck H, Juge F, Roques P (2003) Phylogenetic analysis of the first complete hepatitis E virus (HEV) genome from Africa. FEMS Immunol Med Microbiol 39:133-139

69. van Cuyck-Gandre H, Zhang HY, Tsarev SA, Warren RL, Caudill JD, Snellings NJ, Begot L, Innis BL, Longer CF (2000) Short report: phylogenetically distinct hepatitis $\mathrm{E}$ viruses in Pakistan. Am J Trop Med Hygiene 62:187-189

70. Woo PC, Lau SK, Teng JL, Tsang AK, Joseph M, Wong EY, Tang Y, Sivakumar S, Xie J, Bai R, Wernery R, Wernery U, Yuen KY (2014) New hepatitis $E$ virus genotype in camels, the middle East. Emerg Infect Dis 20:1044-1048

71. Xia H, Liu L, Linde AM, Belak S, Norder H, Widen F (2008) Molecular characterization and phylogenetic analysis of the complete genome of a hepatitis E virus from European swine. Virus Genes 37:39-48
72. Yin S, Purcell RH, Emerson SU (1994) A new Chinese isolate of hepatitis $\mathrm{E}$ virus: comparison with strains recovered from different geographical regions. Virus Genes 9:23-32

73. Zhao C, Ma Z, Harrison TJ, Feng R, Zhang C, Qiao Z, Fan J, Ma H, Li M, Song A, Wang Y (2009) A novel genotype of hepatitis $\mathrm{E}$ virus prevalent among farmed rabbits in China. J Med Virol 81:1371-1379

74. Aggarwal A, Perumpail RB, Tummala S, Ahmed A (2016) Hepatitis $\mathrm{E}$ virus infection in the liver transplant recipients: clinical presentation and management. World J Hepatol 8(2):117-122

75. Allweiss L, Gass S, Giersch K, Groth A, Kah J, Volz T, Rapp G, Schöbel A, Lohse AW, Polywka S, Pischke S, Herker E, Dandri M, Lütgehetmann M (2016) Human liver chimeric mice as a new model of chronic hepatitis E virus infection and preclinical drug evaluation. J Hepatol 64:1033-1040

76. Brayne AB, Dearlove BL, Lester JS, Kosakovsky Pond SL, Frost SDW (2017) Genotype-specific evolution of hepatitis E virus. J Virol 91(9):e02241-e2316

77. Bouquet J, Cheval J, Rogée S, Pavio N, Eloit M (2012) Identical consensus sequence and conserved genomic polymorphism of hepatitis E virus during controlled interspecies transmission. J Virol 86:6238-6245

78. Lu L, Li C, Hagedorn CH (2006) Phylogenetic analysis of global hepatitis $\mathrm{E}$ virus sequences: genetic diversity, subtypes and zoonosis. Rev Med Virol 16(1):5-36

Publisher's Note Springer Nature remains neutral with regard to jurisdictional claims in published maps and institutional affiliations. 